\title{
FATORES DE INTERFERÊNCIA NO PROCESSO DE DOAÇÃO DE ÓRGÃOS E TECIDOS: REVISÃO DA LITERATURA
}

\author{
Interference factors in process and tissue donation of organs: review of literature
}

\author{
Livia Diederichsen de Brito ${ }^{1}$, Rita Gomes Prieb²
}

\section{RESUMO}

O transplante de órgãos e tecidos é uma prática frequente na rotina médica. Para a doação, é necessário apenas o consentimento da família. Todavia, no processo, alguns entraves diminuem o número de doações. Objetivos: Através da revisão da literatura, objetivou-se identificar quais os fatores que interferem no consentimento de familiares de potenciais doadores falecidos após constatação de morte encefálica no processo de doação de órgãos e tecidos. Além disso, procurou-se identificar quais as condições consideradas adequadas para abordagem aos familiares dos potenciais doadores e avaliar o efeito da comunicação da má notícia no consentimento da doação de órgãos e tecidos. Método: Revisão da literatura, utilizando a base de dados OvidMedline, empregando as seguintes palavras-chave: "organ" ou "tissue" e "don*" ou "consent", no período de junho de 2008 a maio de 2012. A busca limitou-se a artigos publicados em língua portuguesa e inglesa e que incluíam seres humanos adultos. Resultados e Discussão: Os fatores de recusa no consentimento mais citados são: dificuldade de compreensão do diagnóstico de morte encefálica, desconhecimento do desejo do falecido sobre a doação dos órgãos, necessidade da família de preservar a integridade do corpo do falecido, divergência de opiniões entre familiares a respeito da doação, tempo escasso para a tomada de decisão de doar e falha na comunicação entre o profissional e a família. O local não se configura como um fator de interferência, sendo somente destacada a importância da realização da entrevista em local privativo. Conclusão: $O$ transplante de órgãos vem se firmando como prática que dá esperança de nova condição de vida para milhares de pessoas que apresentam disfunções diversas. Entretanto, para que isso ocorra, é importante que a captação de órgãos seja efetiva. Diversos fatores são apontados como de possível recusa como os supracitados. Sendo assim, para aumentar o índice de doações é importante que uma equipe de profissionais habilitados seja capacitada e ofereça não só um espaço de continência, mas também de acolhimento à família abordada. Além disso, a comunicação entre os membros da equipe e os familiares deve ser eficaz, favorecendo assim a intenção da doação.

Descritores: Comunicação; Doação de Órgão, Relações Profissional-Família

\begin{abstract}
Instituições:
${ }^{1}$ Residência Integrada Multiprofissional em Saúde - Ênfase Adulto Crítico do Hospital de Clínicas de Porto Alegre, Porto Alegre, Rio Grande do Sul, Brasil ${ }^{2}$ Serviço de Psicologia do Hospital de Clinicas de Porto Alegre, Porto Alegre, Rio Grande do Sul, Brasil
\end{abstract}

Correspondência:

Livia Diederichsen de Brito

Ramiro Barcelos, 2350, Santa Cecília, CEP 90035-903, Porto Alegre/RS

Tel.: 51 9236-4177

E-mail: liviadbrito@hotmail.com

Recebido em: 01.06 .2012

Aceito em: 28.06.2012

\section{INTRODUÇÃO}

O processo de doação de órgãos e tecidos, como o próprio nome sugere, é um processo que se inicia com a identificação e manutenção do paciente diagnosticado com morte encefálica e é concluído com a efetivação do transplante. ${ }^{1}$

A doação de órgãos pode ser feita entre doadores vivos, denominada doação intervivos ou através da doação de um paciente clinicamente morto para um receptor, designada de "doação de doador falecido". A doação de doador falecido é a mais frequente nos processos de transplante, mas a doação intervivos, de acordo com a literatura, é uma prática habitual e que deveria ser vista como uma forma complementar do programa de doação de doador falecido. ${ }^{2}$ A doação de doador falecido somente é realizada após a confirmação da morte encefálica. ${ }^{2}$ De acordo com a Associação Brasileira de Transplantes de Órgãos, ${ }^{3}$ morte encefálica caracteriza-se pela irreversibilidade de todas as funções do cérebro, progredindo assim para o óbito.

Conforme determina o Ministério da Saúde, para ser um doador não é preciso documento de comprovação do desejo da parte do paciente, sendo necessário apenas que a família do doador autorize a doação. ${ }^{4}$ 
No Brasil, assim como em outras partes do mundo, a taxa de recusa no consentimento por parte das famílias é bastante elevada e pode chegar a mais de $50 \% .^{5,6}$ Uma das razões atribuídas à carência na doação de órgãos e tecidos apontados pela literatura é a falha na comunicação entre os profissionais da saúde e a família do doador. ${ }^{7}$

A intervenção psicológica no âmbito hospitalar é bastante ampla, podendo atuar diretamente com o paciente e também como parte de uma equipe multidisciplinar especializada no atendimento de clientelas específicas como, por exemplo, os familiares dos pacientes internados em uma unidade de terapia intensiva. ${ }^{8}$

Tendo em vista a importância do assunto e a participação do profissional psicólogo, como parte da equipe capacitada para a comunicação entre profissionais de saúde e os familiares sobre uma possível doação de órgãos, propôs-se esta revisão, que abordará as possíveis razões de recusa por parte dos familiares para a doação de órgãos de um paciente com diagnóstico de morte encefálica.

\section{OBJETIVO}

Identificar, através de dados publicados na literatura, os fatores que interferem no consentimento dos familiares de potenciais doadores falecidos, após a constatação de morte encefálica no processo de doação de órgãos e tecidos. Além disso, procurouse identificar as condições consideradas adequadas para a abordagem dos familiares de potenciais doadores e avaliar o efeito da comunicação da má notícia no consentimento da doação de órgãos e tecidos.

\section{MÉTODO}

Para a revisão, realizou-se uma busca na base de dados OvidMedline, utilizando os metadados "organ" ou "tissue" e "don" ou "consent". A busca limitou-se a artigos publicados em língua portuguesa e inglesa e que incluíam seres humanos, no período entre junho de 2008 e maio de 2012, que estivessem disponíveis de forma completa e gratuita na rede mundial de computadores. O período de quatro anos para a busca foi definido em razão de já haver outro artigo ${ }^{9}$ que abordou, através de uma revisão sistemática da literatura, o assunto até maio de 2008.

Como critérios de inclusão, foi utilizada a busca por publicações que abordassem: 1) assuntos relativos ao consentimento e resultado da solicitação da doação de órgãos e 2) doação de órgãos de indivíduos adultos.

Como critérios de exclusão foram considerados: 1) artigos em que foi relatada recusa na doação por fatores não modificáveis, tais como religião, cultura, geografia e etnia; 2) que abordaram a doação de órgãos de crianças e adolescentes; 3) estudos que descreveram avaliação neurológica incompleta de pacientes potenciais doadores; e 4) estudos que abordaram somente a parte clínica do processo de doação de órgãos e tecidos.

A busca revelou um total de 1557 artigos relacionados às palavras chaves utilizadas. Para a seleção dos artigos para a revisão, consideraram-se inicialmente os títulos, depois os resumos e, finalmente, o texto completo da publicação.

Todos os 1557 títulos foram avaliados, sendo selecionados 509 resumos. Desses, foram selecionados 32 artigos que foram revisados, alcançando uma seleção de 13 artigos, que foram utilizados para a presente revisão (Figuras 1 e 2).
Figura 1. Fluxograma da seleção dos artigos identificados para o estudo

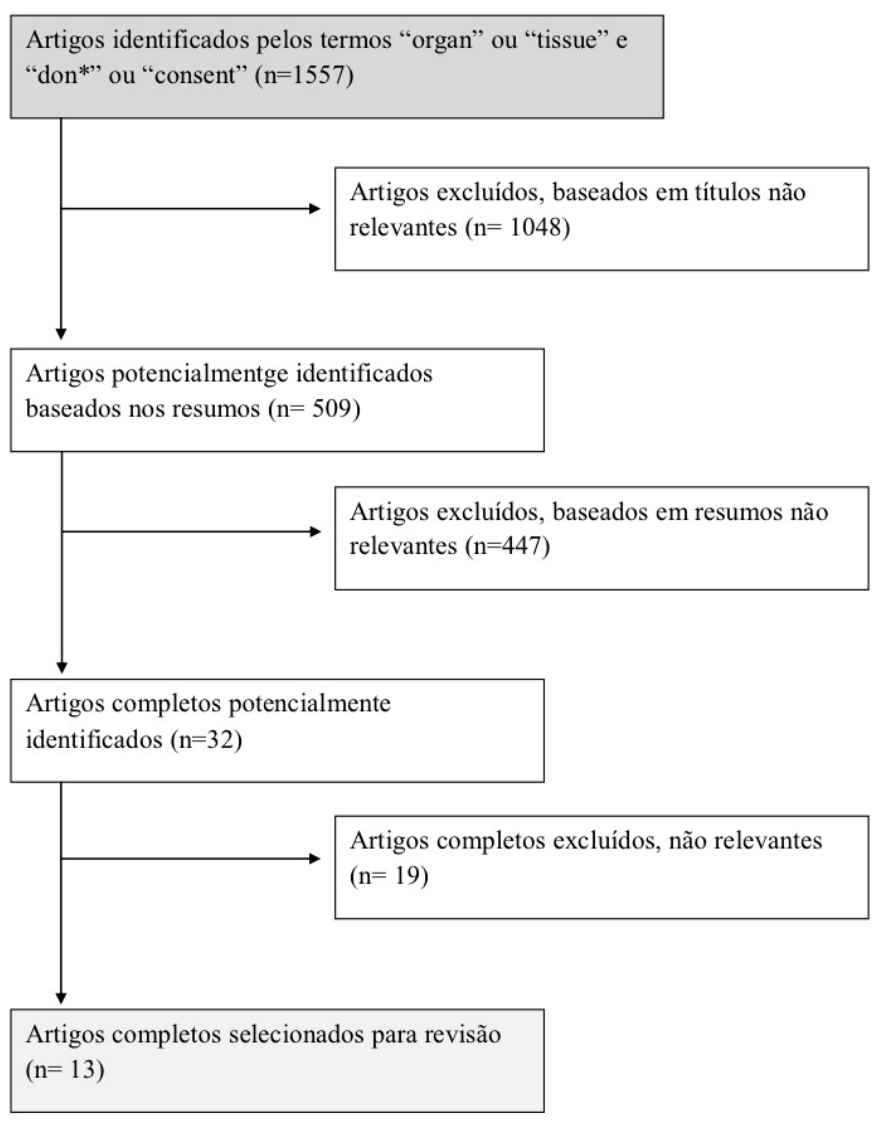

Para a construção da revisão propriamente dita, foi feita uma introdução contemplando alguns conceitos relacionados ao assunto e os resultados posteriormente foram descritos para melhor compreensão.

\section{RESULTADOS}

Diversos fatores são apontados na literatura como fatores de interferência no consentimento de familiares de potenciais doadores no processo de doação de órgãos e tecidos. Os mais frequentemente apontados são:

\section{Diagnóstico de morte encefálica}

A morte encefálica, como já referida, é quando há um cessar de todas as funções das estruturas neurológicas, sendo definida através de alguns testes complementares. ${ }^{10}$ Todavia, muitas vezes ocorre falta de compreensão por parte da família sobre o diagnóstico de morte encefálica, uma vez que, a olhos vistos, o paciente segue apresentando características vitais como batimento cardíaco e outras, como se ainda estivesse gozando de vida plena. É descrito que em muitos casos a comunicação da morte encefálica é feita de forma inadequada, utilizando linguagem complexa e de difícil compreensão., ${ }^{1,911-16}$

\section{Desconhecimento da vontade expressa do paciente falecido}

Outro fator de recusa apontado com frequência é quando a família desconhece o desejo do paciente em relação à doação de órgãos, optando, então, por não consentir na doação. . $^{12,13,16,17}$ 
Figura 2. Razões listadas pelos familiares quanto à recusa na doação de órgãos, que mais apareceram nos artigos revisados.

\begin{tabular}{|c|c|c|}
\hline Achados Principais & Estudo & Autores \\
\hline Inadequação de comunicação entre equipe de saúde e familiares; & $\begin{array}{l}\text { A paradigm shift in the approach to families for } \\
\text { organ donation: honoring patients' wishes versus } \\
\text { request for permission in patients with department of } \\
\text { motor vehicles donor designations }\end{array}$ & Christmas et al, 2008 \\
\hline Diagnóstico de morte encefálica; & $\begin{array}{l}\text { Exploring the psychological effects of deceased organ } \\
\text { donation on the families of the organ donors }\end{array}$ & Merchant et al, 2008 \\
\hline $\begin{array}{l}\text { Diagnóstico de morte encefálica; } \\
\text { Desconhecimento da vontade expressa do paciente falecido; } \\
\text { Preservação da integridade do corpo; } \\
\text { Discordância de opiniões entre familiares; } \\
\text { Inadequação de comunicação entre equipe de saúde e familiares; }\end{array}$ & $\begin{array}{l}\text { A recusa familiar para a doação de órgãos e tecidos } \\
\text { para transplante }\end{array}$ & Moraes et al, 2008 \\
\hline $\begin{array}{l}\text { Discordância de opiniões entre familiares; } \\
\text { Tempo para tomada de decisão; } \\
\text { Inadequação de comunicação entre equipe de saúde e familiares; }\end{array}$ & $\begin{array}{l}\text { Family, patients, and organ and tissue donation: who } \\
\text { decides? }\end{array}$ & Schirmer et al, 2008 \\
\hline $\begin{array}{l}\text { Diagnóstico de morte encefálica; } \\
\text { Tempo para tomada de decisão; } \\
\text { Inadequação de local para conversa; } \\
\text { Inadequação de comunicação entre equipe de saúde e familiares; }\end{array}$ & $\begin{array}{l}\text { Modifiable factors influencing relatives' decision to } \\
\text { offer organ donation: systematic review }\end{array}$ & Simpkin et al, 2008 \\
\hline $\begin{array}{l}\text { Diagnóstico de morte encefálica; } \\
\text { Desconhecimento da vontade expressa do paciente falecido; } \\
\text { Tempo para tomada de decisão; } \\
\text { Discordância de opiniões entre familiares; } \\
\text { Inadequação de local para conversa; }\end{array}$ & $\begin{array}{l}\text { Barriers to obtaining family consent of potential } \\
\text { organ donors }\end{array}$ & Brown et al, 2010 \\
\hline $\begin{array}{l}\text { Diagnóstico de morte encefálica; } \\
\text { Inadequação de comunicação entre equipe de saúde e familiares }\end{array}$ & $\begin{array}{l}\text { Estressores vivenciados pelos familiares no processo } \\
\text { de doação de órgãos e tecidos para transplante }\end{array}$ & Cinque et al, 2010 \\
\hline $\begin{array}{l}\text { Diagnóstico de morte encefálica; } \\
\text { Tempo para tomada de decisão; }\end{array}$ & $\begin{array}{l}\text { Perceived support among families deciding about } \\
\text { organ donation for their loved ones: donor Vs } \\
\text { nondonor next of kin }\end{array}$ & Jacoby, et al, 2010 \\
\hline $\begin{array}{l}\text { Diagnóstico de morte encefálica } \\
\text { Tempo para tomada de decisão; } \\
\text { Inadequação de local para conversa; }\end{array}$ & Organ donation experiences of family members & Manuel et al, 2010 \\
\hline $\begin{array}{l}\text { Desconhecimento da vontade expressa do paciente falecido; } \\
\text { Preservação da integridade do corpo; } \\
\text { Inadequação de comunicação entre equipe de saúde e familiares. }\end{array}$ & Determinants of family consent to tissue donation & Siminoff et al, \\
\hline $\begin{array}{l}\text { Diagnóstico de morte encefálica } \\
\text { Desconhecimento da vontade expressa do paciente falecido; } \\
\text { Preservação da integridade do corpo; } \\
\text { Discordância de opiniões entre familiares; }\end{array}$ & Causes of family refusal for organ donation & Ghorbani et al, 2011 \\
\hline Preservação da integridade do corpo; & $\begin{array}{l}\text { How does the general public view posthumous } \\
\text { organ donation? A meta-synthesis of the qualitative } \\
\text { literature }\end{array}$ & Newton, 2011 \\
\hline Inadequação de comunicação entre equipe de saúde e familiares. & $\begin{array}{l}\text { An exploratory study of relational, persuasive, and } \\
\text { nonverbal communication in requests for tissue } \\
\text { donation }\end{array}$ & Siminoff et al, 2011 \\
\hline
\end{tabular}

\section{Preservação da integridade do corpo}

Alguns autores apontam ainda que a preocupação da família em manter a integridade do corpo do falecido é fator relevante no consentimento para a doação. ${ }^{12,16-18}$

\section{Discordância de opiniões entre familiares}

Outro fator de interferência no consentimento para a doação é a discordância de opinião entre os familiares. A literatura aponta que, quando um membro da família não concorda com a doação, mesmo que os demais estejam de acordo, é comum que a decisão seja tomada conforme a opinião de uma minoria, atitude esta tomada para que não haja maiores conflitos entres os familiares, que já se mostram emocionalmente fragilizados e fisicamente esgotados. . $^{12,13,16,19}$

\section{Tempo para tomada de decisão}

Alguns artigos destacam que, entre a comunicação do diagnóstico de morte encefálica e a solicitação para a doação dos órgãos e tecidos, os familiares não dispõem de tempo suficiente para que a melhor decisão possa ser tomada, havendo assim a negativa no consentimento. ${ }^{9,13-15,19}$

\section{Inadequação de comunicação entre equipe de saúde e familiares}

Receber a notícia de morte encefálica e dos critérios para a comprovação do diagnóstico, de maneira intranquila, no qual há o uso de uma linguagem de difícil compreensão, corrobora para negativa no consentimento. ${ }^{1,6,9,12,17,19,20}$

\section{Inadequação de local para conversa}

Por fim, a adequação do local onde a abordagem com o familiar é realizada também é apontada como fator relevante para a tomada de decisão das famílias, sendo destacada em alguns artigos a importância de se realizar a abordagem em um local privado onde não haja interrupções. ${ }^{9,13,15}$ 


\section{DISCUSSÃO}

O conceito de trocar um órgão enfermo por um órgão sadio remonta da antiguidade e já estava presente em representações de arte medievais. Todavia foi apenas em meados da década de 1960 que essa prática foi efetivamente inserida na rotina médica. ${ }^{21}$

O processo de doação é definido como um conjunto de ações e procedimentos que transformam um potencial doador em um doador efetivo. ${ }^{1,7} \mathrm{O}$ processo inicia-se com a identificação, avaliação e manutenção do paciente diagnosticado com morte encefálica e é concluído com a efetivação do transplante. Contudo, o processo completo inclui diversos passos, como o comunicado da morte a uma central de notificação, captação e distribuição de órgãos; entrevista com os familiares; consentimento familiar; notificação do doador para a central de notificação; captação e distribuição de órgãos; distribuição dos órgãos e tecidos; seleção dos receptores; existência de uma equipe de transplante; extração dos órgãos selecionados e por fim, a liberação do corpo do potencial doador. ${ }^{1}$

O início do processo só ocorre após a comprovação da morte encefálica do paciente, todavia, ele só é efetivado após a autorização de familiares próximos como cônjuges, pais ou filhos, irmãos. ${ }^{22} \mathrm{~A}$ abordagem do(s) familiar(es) é essencial no processo de doação, pois pode culminar com a autorização ou recusa da doação. ${ }^{23}$ Duas condições são apontadas como prioritárias para a adequada comunicação entre profissionais de saúde e familiares: o local onde é realizada a abordagem e a forma com que o entrevistador realiza a abordagem sobre o consentimento da doação. Com relação ao local, no âmbito da psicologia denominamos de "setting". No ambiente hospitalar, deparamo-nos com alguns desajustamentos do "setting", tais como a falta de privacidade e interrupções, além de situações de barulhos e tempo restrito. ${ }^{24}$

Em relação à comunicação entre profissional e família, a forma com que o entrevistador realiza a abordagem sobre o consentimento da doação pode interferir nesse consentimento; sendo assim, o entrevistador deve assumir uma postura adequada, sendo cordial e compreensivo. ${ }^{5,25}$ Tal fator tende a favorecer o vínculo de confiança do familiar para com a equipe e, consequentemente, há uma neutralização da resistência no consentimento por parte da família. ${ }^{26}$ Mesmo em casos em que a decisão recaia na recusa, essa deve ser respeitada. $O$ clima confortável para que o familiar tome sua decisão faz-se necessário, para que sentimentos de coação e culpas não tomem conta desses, reforçando a dor da perda que envolve a notícia do falecimento. ${ }^{5}$

Em diversos países, a doação de órgãos é compulsória. Entretanto, em muitos países delega-se aos familiares a decisão sobre a doação. ${ }^{23}$ Para tanto, os familiares mais próximos, conforme citado anteriormente, são chamados e submetidos a uma entrevista, sendo esse um passo importante no processo de doação, ${ }^{22}$ bem como a forma com que ela é conduzida, já que o consentimento familiar é a chave principal para a efetivação da doação. A família é o elemento primordial no processo e deve receber assistência, antes e depois da notificação da morte encefálica do seu familiar. ${ }^{1}$ Essa assistência prestada não deve ser longa e a equipe deve estar atenta aos primeiros sinais de sofrimento após a notificação da morte, para oferecer ajuda psicológica e auxiliar na tomada de decisão da família diante da doação. ${ }^{23}$
Sendo a comunicação uma habilidade vital para o desenvolvimento do ser humano, na literatura são citadas algumas técnicas para transmissão de uma má notícia que incluem: a escolha e preparação do local onde a notícia será dada; a notícia deverá ser dada de maneira clara e sem eufemismos; todos os questionamentos devem ser respondidos e deve ser oferecido ao familiar um acolhimento. ${ }^{27}$

Alguns autores apontam que, quando a abordagem é realizada de maneira imprópria ${ }^{1}$ ou quando o entrevistador não possui uma postura adequada durante a abordagem, ${ }^{9}$ aumenta a possibilidade da recusa no consentimento por parte da família. Sendo assim, uma simples modificação na abordagem que é realizada com os familiares, atendendo suas demandas psíquicas, poderá aumentar as chances de aceitação da doação. ${ }^{6,23}$ Portanto, promover treinamento aos profissionais que realizam este tipo de abordagem, reforçando sua habilidade empática, ${ }^{17} \mathrm{a}$ fim de estabelecer uma relação de confiança entre o profissional e a família, respeitando a autonomia desta, ${ }^{19}$ é indicado como um fator que favorece a aceitação da doação.

Entretanto, nos artigos analisados, somente é destacada a importância de realizar a comunicação em um local privado, ${ }^{9,13,15}$ sendo esse fator positivo no processo de doação. Todavia, os artigos não ressaltam qual seria a forma de estruturação deste "setting" para que essa abordagem aproxime-se de um possível ideal.

O processo de doação de órgãos é longo e causa intenso sofrimento e desgaste aos familiares. ${ }^{1}$ A falta de tempo para discussão e reflexão sobre a doação entre as familiares do paciente é apontado ${ }^{19}$ como um fator negativo do processo e um dos motivos de recusa no consentimento. Logo, oferecer tempo suficiente para que a família possa decidir sobre a doação é importante, tanto para que a família possa estruturarse internamente, quanto para que a tomada da decisão seja realizada de maneira consciente. ${ }^{9}$

De acordo com a lei brasileira 9.434/1997, ${ }^{28}$ nos casos de captação de órgãos para doação, a família deve receber o corpo do falecido devidamente recuperado, de modo a alcançar tanto quanto possível seu aspecto anterior. ${ }^{1,12}$ Entretanto, essa é uma preocupação apontada por familiares de doadores que se mostram preocupados em preservar a integridade do corpo após o óbito. ${ }^{16,18}$ Desta forma, a recusa é justificada pelo desejo da família de não mutilar e desfigurar o corpo de seu parente, ${ }^{17}$ decisão essa que deve ser respeitada pela equipe que realiza a abordagem.

A morte ainda é um momento traumático que provoca muito estresse às famílias. ${ }^{1}$ Nas situações em que os familiares não possuem a mesma opinião sobre o processo de doação, esse momento estressante pode ainda acarretar desacordos de opiniões e até conflitos entre os familiares. ${ }^{12} \mathrm{~A}$ fim de minimizar um maior estresse nessa família, o familiar favorável pela doação, opta por concordar com o não consentimento evitando assim conflitos maiores entre os demais familiares.

O advento da doação de órgãos e, consequentemente, a aceitação dela, no entanto, inevitavelmente aborda a temática a respeito da morte, ${ }^{8}$ que sempre foi um tema considerado tabu para a espécie humana e ainda hoje vivemos numa sociedade em que pouco se discute sobre ela. ${ }^{29}$

Portanto, oferecer a notícia sobre o diagnóstico de morte encefálica, fazendo uso de uma linguagem simples, explicando os critérios para o diagnóstico e oferecendo tempo para a 
tomada da decisão da família, ${ }^{15}$ pode contribuir para a aceitação do consentimento.

Para ser um doador é necessária apenas a autorização da família, ${ }^{30}$ entretanto, é frequente a família desconhecer o desejo do paciente a respeito da doação de órgão, ${ }^{12,13,16,17}$ sendo esse um fator significativo para a negação do consentimento. É importante conhecer a opinião em vida do falecido a respeito da doação, pois no momento em que a família precisa tomar uma decisão, ela tende respeitar o desejo do indivíduo falecido, sendo a recusa em alguns casos, o comprometimento com o desejo do ente, mas em outros casos, a negação pode ser uma forma da família de amenizar seu próprio sofrimento. ${ }^{12}$

\section{CONSIDERAÇÕES FINAIS}

O transplante de órgãos vem firmando-se como uma prática que dá esperança de uma nova condição de vida para milhares de pessoas que apresentem disfunções diversas. Entretanto, para que isso ocorra, é importante que a captação de órgãos seja efetiva. Para tanto, é necessária a autorização dos familiares do paciente, num processo que pode ser doloroso quando somado ao processo da perda em si dos familiares. Diversos fatores são apontados como de possível recusa, como os supracitados. Entretanto, além desses, outro fator de interferência no processo de doação de órgãos e tecidos, como o pré-atendimento, é indicado na literatura. Contudo esse item não era contemplado nos artigos revisados, não tendo sido incluído na revisão. Sendo assim, para aumentar o índice de doação, é importante que uma equipe de profissionais habilitados seja capacitada e que essa ofereça não só um espaço de continência, mas também de acolhimento à família abordada. Além disso, a comunicação entre os membros da equipe e os familiares deve ser eficaz, favorecendo assim a intenção de doação.

A inserção do psicólogo no ambiente hospitalar tem ocorrido gradualmente com o passar do tempo. Cada vez mais, o profissional da psicologia encontra-se inserido em diversas áreas do hospital, fazendo parte de equipes multiprofissionais. Hoje, não só o tratamento direto do paciente está entre as funções do psicólogo, mas também o acolhimento e acompanhamento aos familiares de pacientes internados, por exemplo, em uma unidade de terapia intensiva.

É premente a capacitação da equipe de profissionais para realizar a abordagem, e que haja um ambiente específico e apropriado para a realização do diálogo. A criação de um protocolo de entrevista com familiares poderia ser uma alternativa, de modo a auxiliar os profissionais durante a abordagem da doação. Além disso, é importante a divulgação a respeito da doação de órgãos através de campanhas educativas para fazer a população em geral discutir o assunto no âmbito familiar e social.

\section{ABSTRACT}

Organ and tissue transplantation is an increasingly common practice in medical routine. In Brazil, to donate the only requirement is the relatives' consent. However, the amount of donation is often reduced due to some barriers. Purposes: By a literature review aimed to identify factors affecting the consent of relatives of the dead body of potential donors after brain death in the process of organ donation. In addition, we seek to identify what conditions it is appropriate to deal with the families of potential donors and also to evaluate the effect of bad news on the consent of organ and tissue donation. Methods: The study was conducted through a literature review using the OvidMedline database using the keywords "organ" or "tissue" and "don*" or "consent", from June 2008 to May 2012. The search was limited to articles published in Portuguese and English and that included adult humans. Results and Discussion: The factors to refuse consent most cited were difficulty in understanding the diagnosis of brain death, ignorance of the deceased's wishes about organ donation, the family's desire to preserve the integrity of the body of the deceased, divergence of opinions among the families about the donation, the scarce time for the decision to donate and the failure in communication between the family and the health care professional. The setting for discussion is not set up as interference factor for donation but it was only highlighted the importance of conducting the interview in a private location. Conclusion: Organ transplantation is establishing itself as a practice that gives hope of a new condition of life for thousands of people who have various dysfunctions. However, for this to occur, it is important that organ harvesting is effective. Several factors are cited as possible refusal as above. For that reason, to increase the rate of donation, it is important that a team of skilled and qualified professionals is that not only provides a forum for continence, but also addressed the host family. Furthermore, communication between team members and family members must be effective, thus favoring the intention of donation.

Keywords: Communication, Organ Donors, Professional-Family Relations.

\section{AGRADECIMENTO}

Agradeço à Wilia Marta E. D. de Brito pela dedicação e colaboração intelectual neste trabalho, ao psicólogo e também amigo, Rodrigo Souza, pelo auxílio técnico. Agradeço ainda, os médicos Ricardo Kuchenbecker e Cristiano Franke e ao biólogo José Roberto Goldim pelas sugestões na elaboração deste. 


\section{REFERÊNCIAS:}

1. Cinque VM, Bianchi ERF. Estressores vivenciados pelos familiares no processo de doação de órgãos e tecidos para transplante. Rev Esc Enferm USP. 2010;44(4):996-1002.

2. Manyalich M, Paredes D, Vilardell J. Aspectos generales. In: Matesanz R, et al. El modelo Español de Coordinación y Trasplantes. Madrid: Aula Médica; 2008. p.181-85.

3. ABTO: Associação Brasileira de Transplantes de Órgãos. 2011. Disponível em: http://www.abto.org.br/abtov02/portugues/populacao/doacaoOrgaosTecidos/ entendendoMorteEncefalica.aspx?idCategoria $=4$.

4. Brasil Ministério da Saúde. Portal da Saúde: Transplantes. 2011. Disponível em: http://portal.saude.gov.br/portal/saude/area.cfm?id_area=1004.

5. Rech TH, Rodrigues EMF. Entrevista familiar e consentimento. Rev Bras Terap Intensiva. 2007;19(1):85-9.

6. Christmas AB, Mallico EJ, Burris GW, Bogart TA, Norton AJ, Sing RF. A paradigm shift in the approach to families for organ donation: honoring patients' wishes versus request for permission in patients with department of motor vehicles donor designations. The Journal of Trauma. 2008;65(5):1507-10.

7. Santos MJ, Massarollo MCKB. Processo de doação de órgãos: percepção de familiares de doadores cadáveres. Rev Latino-am Enfermagem. 2005;13(3):382-87.

8. Amorim SF. Intervenção psicológica no hospital geral. In: Bruscato W, Benedetti C, Lopes SRA, et al. A prática da psicologia hospitalar na Santa Casa de São Paulo. São Paulo: Casa do Psicólogo; 2004. p.71-8.

9. Simpkin AL, Robertson LC, Barber V, Young JD. Modifiable factors influencing relatives' decision to offer organ donation: systematic review. BMJ. 2009 Apr 21;338:b991

10. Escudero D. La muerte encefálica exploración clínica y métodos diagnósticos instrumentales. In: Matesanz R, et al. El modelo Español de Coordinación y Trasplantes. Madrid: Aula Médica; 2008. p.121-34.

11. Merchant SJ, Yoshida EM, Lee TK, Richardson P, Karlsbjerg KM, Cheung E. Exploring the psychological effects of deceased organ donation on the families of the organ donors. Clin Transplant. 2008;22:341-47.

12. Moraes EL, Massarollo MCKB. A recusa familiar para a doação de órgãos e tecidos para transplante. Rev Latino-am Emfermagem. 2008;16(3):458-64

13. Brown CVR, Foulkrod KH, Dworaczyk S, Thompson K, Elliot E, Cooper $\mathrm{H}$, et al. Barriers to obtaining family consent for potential organ donors. The Journal of Trauma. 2010;68(2):447-51.

14. Jacoby L, Jaccard J. Perceived support among families deciding about organ donation for their loved ones: donor Vs nondonor next of kin. Am J Crit Care. 2010;19:52-61.
15. Manuel A, Solberg S, MacDonald S. Organ donation experiences of family members. Nephorology Nursing Journal. 2010;37(3):299-37.

16. Ghorbani F, Khoddami-Vishteh HR, Ghobadi O, Shafaghi S, Louyeh AR, Najafizadeh K. Causes of family refusal for organ donation. Transplant Proceedings. 2011;43:405-06.

17. Siminoff LA, Traino HM, Gordon N. Determinants of family consent to tissue donation. The Journal of Trauma. 2010;69(4):956-63.

18. Newton JD. How does the general public view posthumous organ donation? A meta-synthesis of the qualitative literature. BMC Public Health. 2011;11:791.

19. Schirmer J, Roza BA. Family, patients, and organ and tissue donation: Who decides? Transplant Proceedings. 2008;40:1037-40

20. Siminoff LA, Traino HM, Gordon NH. An exploratory study of relational, persuasive, and nonverbal communication in requests for tissue donation. $\mathbf{J}$ Health Commun. 2011;16(9):955-75.

21. Matesanz R. Los inicios de lós trasplantes em España y em el mundo. In: Matesanz R, et al. El modelo Español de Coordinación y Trasplantes. Madrid: Aula Médica; 2008. p.1-9.

22. Griffith R, Tengnah C. Consent to organ donation part 1 : the current arrangements. British Journal of Community Nursing. 2009;14(12):544-47.

23. Santiago PGC. La entrevista familiar técnica y resultados. In: Matesanz R, et al. El modelo Español de Coordinación y Trasplantes. Madrid: Aula Médica; 2008. p.105-19.

24. Simonetti A. Manual de psicologia hospitalar o mapa da doença. São Paulo: Casa do Psicólogo; 2004.

25. Martins CM, Cosmo M. A centralidade da família no processo de doação de órgãos e tecidos. J Bras Transpl. 2009:12(4):1169-220.

26. Quintana AM, Arpini DM. Doação de órgãos: possíveis elementos de resistência e aceitação. Bol. de Psi. 2009;609(130):91-102.

27. Leal F. Transmissão de más notícias. Rev Port Clin Geral. 2001;19;40-3.

28. Brasil. Lei n. 9.434, de 4 de fevereiro de 1997. Dispõe sobre a remoção de órgãos, tecidos e partes do corpo humano para fins de transplante, e dá outras providências. Diário Oficial da União, Brasília, 5 fev. 1997. P.2191-3.

29. Kübler-ross E. Sobre a morte e o morrer. São Paulo: Martins Fontes; 1998.

30. Brasil Ministério da Saúde. Portaria MS no 1.262, de junho de 2006 - DOU 19.06.2006. Disponível em: http://www.adote.org.br/pdf/portaria_1262. pdf. 